\title{
Survival analysis of neonatal mortality in Ghana using three population-based surveys
}

David Teye Doku ${ }^{1,2}$ (1)

\begin{abstract}
Background: Neonatal mortality in many low-and middle-income countries (LMICS) remains high despite global efforts at addressing this challenge. Tackling neonatal death in LMICs is further complicated by lack of reliable data from individual countries in the region to inform effective context specific interventions. This study investigates the probability of neonatal survival and socio-demographic risk factors of neonatal mortality in Ghana.

Methods: Pooled data from three population-based surveys $(N=12,148)$ were analysed using multivariable Cox Proportional Hazards regression models.

Results: The risk of dying within the first 28 days of life was highest in the first week of life (early neonatal period), it then decreases sharply around the middle of the second week of life and remains low over the late neonatal period. Adjusted hazard ratios (HRs) showed that: rural residency $(H R=1.80,95 \% \mathrm{Cl}: 1.15-2.75)$; birth order 2-3 ( $H R=$ 1.63, 95\% Cl: 1.10-2.42); birth order $\geq 7(\mathrm{HR}=1.89,95 \% \mathrm{Cl}: 1.07-3.33)$ increased the risk of neonatal death.

Additionally, children born to women who were obese had higher risk of neonatal death ( $H R=1.69, \mathrm{Cl}$ : 1.12-2.56)

compared with those of women with optimal weight. Disparities in the risk of neonatal death by geographical regions were also found.

Conclusion: The risk of neonatal mortality is highest during the first week of life and it is sociodemographically patterned. The findings emphasise the need to tackle socio-demographic risk factors of neonatal mortality in order to achieve the Sustainable Development Goal 3, which is aimed at reducing neonatal mortality to 12 per 1000 live births by the year 2030.
\end{abstract}

Keywords: Neonatal mortality, Survival analysis, Ghana

\section{Background}

Child mortality has decreased globally over the past one and half decades. However, the levels in most low- and middle-income countries (LMICs), particularly, in SubSaharan Africa is unacceptably high. The phenomenon constitutes a global public health challenge and accounts for inequalities in health between and within high

Correspondence: dokudavid@gmail.com; ddoku@ucc.edu.gh

${ }^{1}$ Department of Population and Health, University of Cape Coast, Cape Coast, Ghana

${ }^{2}$ Directorate of Research, Innovation and Consultancy (DRIC), University of Cape Coast, Cape Coast, Ghana income countries and low- and middle-income countries (LMICs) [1]. In 2015, 5.9 million died before their fifth birthday [2, 3], and 2.9 million of these were neonatal mortality, babies who die within the first 28 days of life, thus neonatal mortality constitutes the largest proportion of under-five mortality. About four million babies die within the new born or neonatal period and nearly all of these deaths occur mainly in LMICs [1-3]. In these countries, new born deaths account for $41 \%$ of all child deaths.

(c) The Author(s). 2022 Open Access This article is licensed under a Creative Commons Attribution 4.0 International License, which permits use, sharing, adaptation, distribution and reproduction in any medium or format, as long as you give appropriate credit to the original author(s) and the source, provide a link to the Creative Commons licence, and indicate if changes were made. The images or other third party material in this article are included in the article's Creative Commons licence, unless indicated otherwise in a credit line to the material. If material is not included in the article's Creative Commons licence and your intended use is not permitted by statutory regulation or exceeds the permitted use, you will need to obtain permission directly from the copyright holder. To view a copy of this licence, visit http://creativecommons.org/licenses/by/4.0/ The Creative Commons Public Domain Dedication waiver (http://creativecommons.org/publicdomain/zero/1.0/) applies to the data made available in this article, unless otherwise stated in a credit line to the data. 
Public health interventions undertaken since 1990 to reduce under-five mortality have been mainly driven by the Millennium Development Goal (MDG) 4, which aimed at a two-thirds reduction in mortality risks of children under-five between 1990 and 2015. Consequently, many LMICs have reduced the proportion of children who died before their fifth birthdays. Despite the success achieved through the MDGs over the past one and half decades, neonatal mortality figures are still unacceptably high in most LMICs. With a few exceptions, Sub-Saharan Africa is among the regions, which did not meet the MGDs targets. Over all, among the LMICs, Sub-Saharan African countries have the largest burden of neonatal mortality.

Improvement in neonatal, infant and child mortality is an important public health goal of the government of Ghana. Over the past one and half decades this goal has led to a significant reduction in the overall child mortality in the country [4]. However, Ghana is one of the countries, which could not meet the MDG 4, of reducing by two thirds the under-five mortality between 1990 and 2015 [4]. In particular, the proportion of neonatal mortality within the child mortality remains high [4]. The most recent national representative survey conducted in 2014 suggests that among births 5 year preceding the survey, neonatal mortality rate is 29 per 1000 livebirth and this constitutes 2.2 folds of the post-neonatal mortality rate [4]. To make any progress toward the realisation of the Sustainable Development Goal (SDG) 3 target 3.2, which aims at reducing neonatal mortality to 12 per 1000 live births by the years 2030 [5], it is necessary to understand the risk factors for neonatal death. Quality data that provide country specific analysis of the situation to facilitate contextual interventions are critical.

Analysis of neonatal mortality in Sub-Saharan Africa including Ghana using population level data is rare. Only a handful of studies have conducted analysis of neonatal deaths in Ghana. Kayode, et al. [6] investigated the individual and community level factors influencing neonatal death in Ghana using surveys conducted in 2003 and 2008. However, studies that will increase our understanding of the time-to-event perspective of the phenomenon are essential for monitoring the impact of public health interventions geared towards reducing the burden of neonatal mortality, especially targeted interventions at critical time points during the neonatal period are essential. This study utilised pooled data from three nationally representative surveys to investigate the socio-demographic risk factors of neonatal mortality in Ghana.

\section{Methods}

\section{Data source}

This study used pooled nationally representative data from three cross-sectional surveys conducted in 2003,
2008 and 2014 in the Ghana version of the Demographic and Health Surveys (DHS), in order to ensure enough power, for the purpose of neonatal mortality risk analysis. The DHS uses a standardized questionnaire and methodology for data collection in order to facilitate international comparison in LMICs. The DHS have been conducted in nearly all LMICs since early 1990s. The Surveys have generated high quality data on significant demographic, economic, social and health for low- and middle-income countries and have been used in high quality research, which have contributed to the literature from these regions (http://dhsprogram.com/ Publications/Journal-Articles-by-Journal.cfm). All the three surveys data analysed in this study were collected using two stage sampling approach based on the 2000 (for the 2003 and 2008 surveys) and 2010 (for the 2014 survey) Ghana Population and Housing Censuses to produce separate estimates for key indicators for each of the ten regions in Ghana. Sample clusters were selected from an updated master sampling frame constructed from the Ghana Population and Housing Censuses in the first stage of the sampling. The clusters were selected using systematic sampling with probability proportional to the population size. The second stage of selection involved systematic sampling of 30 of the households listed in each cluster. This was done to ensure adequate numbers of completed individual interviews to provide estimates for key indicators with acceptable precision and to provide a sample large enough to identify adequate numbers of under-five deaths to provide data on causes of death. Details of the DHS is published elsewhere (http://www.dhsprogram.com/data/datacollection.cfm). The outcome of singleton livebirths for each woman within the 5 years preceding the survey was considered in this study. The survey documented detailed information on the birth histories on livebirths for each woman in the reproductive age (15-49 years). This includes, the month and year of each birth, any multiple pregnancies, whether child was alive or dead, current age and age of death (if dead). Age at death was recorded in days if the child dies within 1 month of birth. Ethical clearance for the Ghana surveys was obtained from the Ghana Health Service Research Ethics Committee in Accra and permission to analyse the data was obtained from Measure DHS. Data for the study are publicly available and can be requested from Measure DHS through https://dhsprogram.com/data/availabledatasets.cfm.

\section{Variables}

The outcome variable for this study was neonatal death, which is defined as death of a live born within the first 28 days of life in accordance with the WHO definition of neonatal death. The independent variables used in this 
study are; maternal age (categorised in years as $<25,25$ $29,30-34,35-39,40-44$, and 45-49), place of residence (categorised as rural urban) and body mass index (BMI). BMI was computed based on two anthropometric measurements (weight and height) taken during the surveys. It was calculated by dividing body weight $(\mathrm{kg})$ by height squared $\left(\mathrm{m}^{2}\right)$ and categorised into; underweight $<18.5$ $\mathrm{kg} / \mathrm{m}^{2}$, normal weight $=18.5-24.9 \mathrm{~kg} / \mathrm{m}^{2}$, overweight $=$ $25.0-29.9 \mathrm{~kg} / \mathrm{m}^{2}$ and obese $>=30.0 \mathrm{~kg} / \mathrm{m}^{2}$. The rest of the independent variables are: birth order (categorised as first birth, second or third birth, 4th - 6th birth, > 6th birth), maternal education (categorised as no education, primary, secondary or higher) and wealth index quintile. The wealth index quintile is a composite measure of a household's cumulative living standard based on ownership of specified assets generated from principal components analysis and categorised into quintiles as poorest, poorer, middle, richer and richest [7].

\section{Statistical analysis}

DHS conducted editing and imputation of missing procedures before the data were released. For records for which days of birth were missing, 15th day of the month was imputed to estimate the survival time in days. We used Cox Proportional hazard regression to estimate the hazard ratios (HRs) with their 95\% confidence intervals (CIs) for neonatal mortality, which is given by $h(t)=$ $h_{0}(t) \exp \left[b_{1} x_{1}\right]$, where $x_{1}$ is the covariate to the hazard $h(t)$ at time $t$ [8]. Given follow-up time as $\mathrm{t}_{1}, \mathrm{t}_{2}, \mathrm{t}_{3}, \mathrm{t}_{4}, \ldots$ $t_{k}$, where $k$ is the number of patients/participants. In this study, the follow-up time for each neonate is the period from birth to death or the date of the survey, whichever occurs first. The assumption is that each event (outcome) occurs independently, hence the probability of no event (survival) between each time point is multiplied together to obtain the cumulative survival probability. The probability of being alive at time $t_{j}, S\left(t_{j}\right)$, is calculated from $S\left(t_{j-1}\right)$ the probability of being alive at $t_{j-1}$, $n_{j}$ the number of patients alive just before $t_{j}$, and $d_{j}$ the number of events at $t_{j}$, is given by the formula.

$$
S\left(t_{j}\right)=S\left(t_{j}-1\right)\left(1-\frac{d_{j}}{n_{j}}\right)
$$

where $t_{0}=0$ and $S(0)=1$. The estimated probability function is a step which changes values at each time of the event since $\mathrm{S}(\mathrm{t})$ is a constant variable $[8,9]$. Adjusted hazard ratios for neonatal death were calculated for the total sample adjusting for each of the independent variables. The survey commands in Stata were used to account for the effect of the multi-stage cluster sampling on the estimates. The proportionality assumption of the multivariate survival model was tested using the Schoenfeld residuals diagnostic test and graphically examined with $\log (-\log$ Survival) curves. These tests confirmed the adequacy of the multivariable model. Smoothed hazard functions stratified by rural-urban and BMI were used to investigate the differences in neonatal mortality rates. All statistical analysis were conducted using STATA/SE 14.0.

\section{Results}

This study used high quality data pooled from three population-based studies conducted in 2003, 2008 and 2014 to investigate socio-demographic risk factors of neonatal mortality in Ghana. The weighted distribution of the independent variables and the pooled value for the three surveys are presented in Table 1 . The pooled sample resulted in 12,148 respondents for this study. Table 1 also shows the distribution of neonatal death by the background characteristics. Women aged 25-29 years formed the largest proportion $(26.3 \%)$ of the sample and those within the last 5 years of their reproductive age (45-49) were the smallest group (3.1\%) by age categorisation. Majority $(60.5 \%)$ of the respondents were in urban areas which is a reflection of the growing urbanisation in most LMICs including Ghana. Births within 5 years of the surveys were mainly in the birth order one (37.3\%) and as expected the least proportion of births were in birth order seven or more $(9.3 \%)$. A third of the women had no formal education, $22.1 \%$ had primary education and $45.4 \%$ had secondary education or higher. One-fifth of the women could be described as poorest while $16.1 \%$ were in the richest category by wealth index. Also, a third of the women were either overweight $(\mathrm{BMI}=25.0$ 29.9 ) or obese (BMI $>=30.0$ ) while $6.8 \%$ were underweight (BMI < 18.5). The Greater Accra region, which is the region in which the capital city (Accra) is located, had the lowest sample in this study $(2.4 \%)$ while the Northern region had the highest proportion (15.8\%).

Adjusted hazard ratios (HRs) investigating the relationship between neonatal mortality and key characteristics of the sample are presented in the fourth column of Table 1. Rural residence ( $\mathrm{HR}=1.80,95 \% \mathrm{CI}: 1.15-2.75)$ increased the risk of neonatal death compared with urban residence; birth order $2-3(\mathrm{HR}=1.63,95 \% \mathrm{CI}$ : $1.10-2.42)$ or having birth order seven or more $(\mathrm{HR}=$ 1.89, 95\% CI: 1.07-3.33) increased the risk of neonatal death compared with women who were nulliparous; and children born to women who were obese had higher risk of neonatal death (HR $=1.69,95 \% \mathrm{CI}$ : 1.12-2.56) compared with those of women with optimal weight. Differences in neonatal mortality were also found by regions such that Volta $(\mathrm{HR}=2.04,95 \% \mathrm{CI}: 1.11-3.76)$, Eastern $(\mathrm{HR}=1.79,95 \% \mathrm{CI}: 1.01-3.14)$ Ashanti $(\mathrm{HR}=2.40,95 \%$ CI: 1.40-4.17) and Upper West (HR $=1.98,95 \%$ CI: 1.033.81) regions had higher risk of neonatal death compared to those in the Greater Accra region. Furthermore, 
Table 1 Association of maternal characteristics and neonatal mortality in Ghana

\begin{tabular}{|c|c|c|c|}
\hline Variable & N (\%) & Neonatal deaths & Adjusted hazard ratios $^{\mathrm{a}}$ \\
\hline \multicolumn{4}{|l|}{ Maternal age } \\
\hline$<25$ & $2604(22.3 \%)$ & $21.2 \%$ & 1.00 \\
\hline $25-29$ & $3071(26.3 \%)$ & $19.5 \%$ & $0.78(0.49-1.24)$ \\
\hline $30-34$ & $2646(22.7 \%)$ & $23.9 \%$ & $1.32(0.81-2.14)$ \\
\hline $35-39$ & $2052(17.6 \%)$ & $19.5 \%$ & $1.18(0.69-2.04)$ \\
\hline $40-44$ & $951(8.1 \%)$ & $11.2 \%$ & $1.18(0.56-2.47)$ \\
\hline $45-49$ & $356(3.1 \%)$ & $4.7 \%$ & $1.51(0.61-3.67)$ \\
\hline \multicolumn{4}{|l|}{ Place of residence } \\
\hline Urban & $7070(60.5 \%)$ & $36.4 \%$ & 1.00 \\
\hline Rural & $4611(39.5 \%)$ & $63.6 \%$ & $1.80(1.18-2.75)$ \\
\hline \multicolumn{4}{|l|}{ Birth order } \\
\hline $2-3$ & $4353(37.3 \%)$ & $28.1 \%$ & 1.00 \\
\hline First & $2843(24.3 \%)$ & $31.4 \%$ & $1.63(1.10-2.42)$ \\
\hline $4-6$ & 3403 (29.1\%) & $25.7 \%$ & $1.01(0.67-1.53)$ \\
\hline$\geq 7$ & $1081(9.3 \%)$ & $14.8 \%$ & $1.89(1.07-3.33)$ \\
\hline \multicolumn{4}{|l|}{ Maternal education } \\
\hline No education & 3807 (32.6\%) & $31.7 \%$ & 1.00 \\
\hline Primary education & $2576(22.1 \%)$ & $24.9 \%$ & $1.27(0.85-1.89)$ \\
\hline Secondary or Higher Education & $5298(45.4 \%)$ & $43.5 \%$ & $0.88(0.59-1.34)$ \\
\hline \multicolumn{4}{|l|}{ Wealth index } \\
\hline Poorest & 2817 (24.1\%) & $23.1 \%$ & 1.00 \\
\hline Poorer & $2541(21.8 \%)$ & $19.0 \%$ & $0.84(0.52-1.37)$ \\
\hline Middle & 2277 (19.5\%) & $21.1 \%$ & $1.37(0.83-2.26)$ \\
\hline Richer & $2165(18.5 \%)$ & $17.8 \%$ & $1.26(0.67-2.36)$ \\
\hline Richest & $1880(16.1 \%)$ & $19.0 \%$ & $1.52(0.76-3.06)$ \\
\hline \multicolumn{4}{|l|}{ BMI } \\
\hline Optimum weight & 5532 (61.0\%) & $53.8 \%$ & 1.00 \\
\hline Underweight & $614(6.8 \%)$ & $6.8 \%$ & $1.35(0.91-2.00)$ \\
\hline Overweight & 1847 (20.4\%) & $22.9 \%$ & $1.07(0.61-1.89)$ \\
\hline Obese & 1077 (11.9\%) & $16.5 \%$ & $1.69(1.12-2.56)$ \\
\hline \multicolumn{4}{|l|}{ Region } \\
\hline Greater Accra & $1026(2.4 \%)$ & $7.7 \%$ & 1.00 \\
\hline Central & $1020(8.4 \%)$ & $9.5 \%$ & $1.60(0.89-2.91)$ \\
\hline Western & $1146(9.4 \%)$ & $8.3 \%$ & $1.42(0.78-2.59)$ \\
\hline Volta & 949 (7.8\%) & $9.5 \%$ & $2.04(1.11-3.76)$ \\
\hline Eastern & $1070(8.8 \%)$ & $10.1 \%$ & $1.79(1.01-3.14)$ \\
\hline Ashanti & 1558 (12.8\%) & $26.6 \%$ & $2.41(1.40-4.17)$ \\
\hline Brong Ahafo & 1312 (10.8\%) & $10.1 \%$ & $1.78(0.96-3.31)$ \\
\hline Northern & 1920 (15.8\%) & $11.2 \%$ & $1.40(0.79-2.50)$ \\
\hline Upper East & $1103(9.1 \%)$ & $3.5 \%$ & $1.20(0.60-2.39)$ \\
\hline Upper West & $1044(8.6 \%)$ & $4.1 \%$ & $1.98(1.03-3.81)$ \\
\hline Pooled sample & $12,148(100.0 \%)$ & $100 \%$ & \\
\hline
\end{tabular}

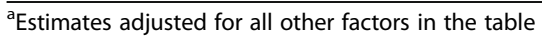


maternal age, primary school attainment (compared to no education), wealth index, underweight, and those in the Central, Western, Brong Ahafo, Northern and Upper East regions (compared to those in the Greater Accra region) had higher risk of neonatal death, although these estimates did not reach statistically significant level $(p<$ 0.05).

Figure 1 shows the daily hazard of neonatal mortality over time. The risk of dying within the first 28 days of life was highest in the first week of life (early neonatal), it then decreases sharply around the middle of the second week of life and then remains low over the late neonatal period. Neonatal survival among obese and nonobese women is presented in Fig. 2. The risk of dying during the first 28 days of life was high for both groups in the early neonatal period and no differences were found between the two groups during this period. The probability of surviving then sharply falls among obese women creating differences between the two groups throughout the neonatal period. Figure 3 shows the smoothed hazard function for 28 days by the place of residence. The risk of neonatal death was higher for those in urban residence during the first week of life (early neonatal period). However, the risk becomes high for rural folks during the second week while no difference was observed during the late neonatal period (Fig. 3).

\section{Discussion}

The study suggests that the risk of dying within the first 28 days of life was highest in the first week of life (early neonatal period), it then decreases sharply around the middle of the second week of life and then remains low over the late neonatal period. Rural residency, birth order 2-3 and seven or more birth order, and maternal obesity are risk factors for neonatal death among children in Ghana. In addition, regional differences in the

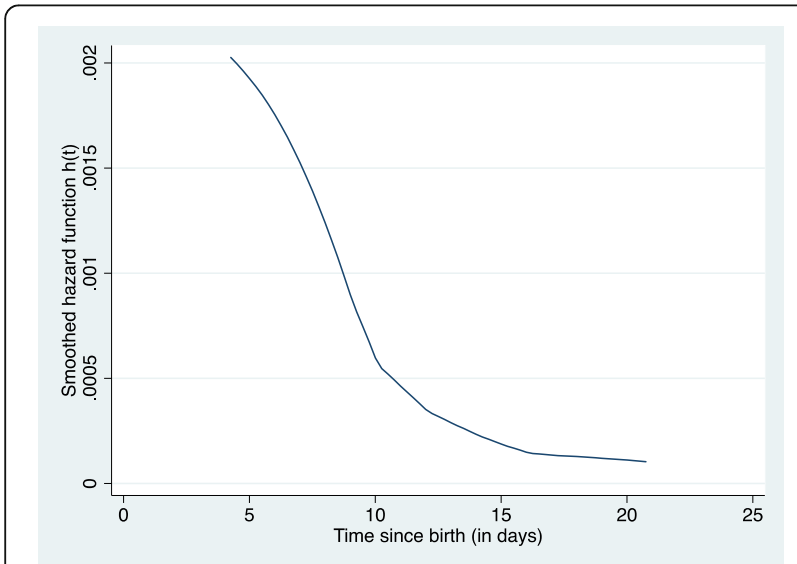

Fig. 1 Daily hazard of death for neonates during the first month of life in Ghana from 2003 to 2014

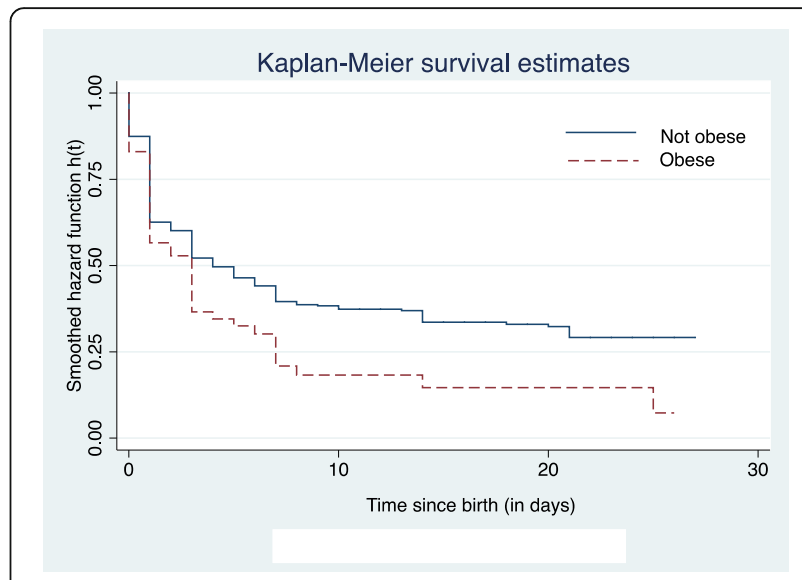

Fig. 2 Daily survival estimate for neonates in Ghana from 2003 to 2014 by maternal body mass index

risk of dying during the first 28 days of life were found such that Volta, Eastern, Ashanti and Upper West regions had higher risk of neonatal death compared to the Greater Accra region. Furthermore, the finding suggests that these risks of neonatal mortality were highest during the first week of life.

Consistent with previous findings, older maternal age was found to be a risk factor for neonatal mortality in this study, albeit not statistically significant [10]. Kozuki, et al. (2013) [11] in a meta-analysis investigating the associations of parity and maternal age with small-forgestational-age, preterm delivery and neonatal and infant mortality, found that women with birth 2-3 nulliparous who were aged $<18$, compared with women who had parity $1-2$ and aged $18-<35$ years had the highest odds of preterm and neonatal mortality. Increased risk of neonatal death observed among those with birth order seven or more also supports the aforementioned literature. The relationships between neonatal mortality and both age and birth order have biological plausibility. More so,

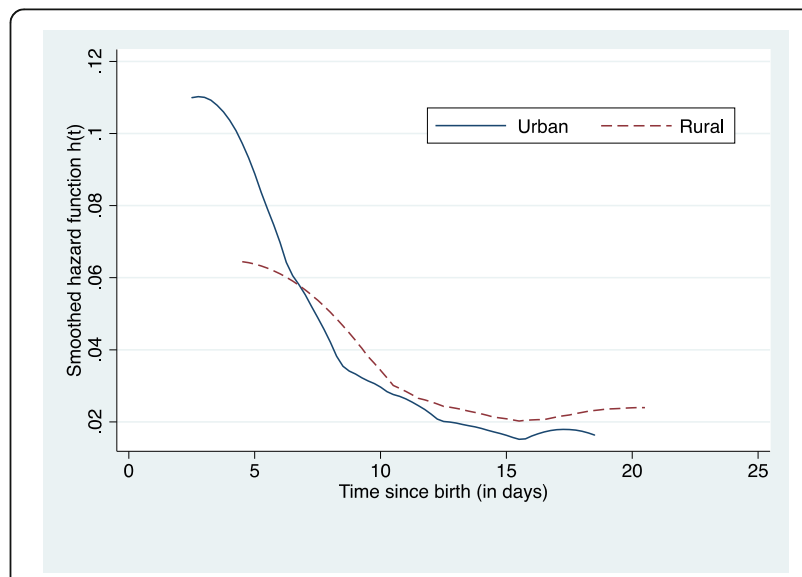

Fig. 3 Daily hazard of death for neonates during the first month of life in Ghana from 2003 to 2014 by place of residence 
some previous studies have found differences in maternal health utilisation by maternal experience, in terms of age and birth order which could explain partly the association found here [12-14].

A number of earlier studies have documented disparities in the important child health outcomes including child mortality and nutrition between rural and urban setting in the LMICs [15-19]. Most of these studies have found differences in maternal and child related outcomes to the disadvantage of rural dwellers $[16,17]$ but a couple of them also found differences to the peril of urban populations [20]. Several factors, including practices related to child care at early days of life, are known to affect child mortality $[17,18]$ but how these factors relate to neonatal mortality has been rarely studied. Higher risk of neonatal mortality for rural areas compared to urban areas may reflect the distribution of antenatal healthcare services, both in terms of quality and access, between the two settings similar to those found in other studies [19, 21]. Disparities between antennal care utilisation also exist in Ghana [14, 22]. Further, although antenatal coverage is high in Ghana (97\%), health facility delivery is less (74\%), particularly, in rural communities. Sixty percent of women in rural areas deliver in health facilities compared to $90 \%$ of those in urban areas [22]. These factors may have contributed to the rural-urban disparities as well as the regional differences in the neonatal mortality found in this study. There are individual level characteristics, which may have specific influence on neonatal health irrespective of clustered characteristics at the community levels.

Another interesting finding in this study is that maternal obesity was associated with increased risk of neonatal death. When this relationship was investigated graphically, it was also found that the risk associated with obesity and neonatal mortality is highest during the early neonatal period. This finding is consistent with those found in SubSaharan population-based study [23]. Obesity co-morbid with other risks such as gestational diabetes, preeclampsia and hypertension all of which could affect the growth and development of the foetus and consequently affect neonatal survival. Recent investigations have reported alarming rise in obesity among women in SubSaharan Africa [24] as well as in Ghana [25]. Considering the rising obesity epidemic, the effect of obesity on neonatal mortality found here deserves attention. It emphasises the need for a holistic approach in accelerating the slow progress made so far in addressing child mortality in general and neonatal mortality in particular.

Wealth index, which measured the household asset of the respondents, seems to have a positive gradient with neonatal mortality. Cresswell, et al. [23] presented similar relationship. Although in this study this relationship was not statistically significant, probably due to few cases, this counterintuitive finding deserves further investigation. Children of women living in regions other than the Greater Accra region had increased risk of neonatal death. The Greater Accra region being the region which houses the capital city is likely to have the most well equipped private and government health facilities for gynaecology, obstetrics and paediatric services compared to the other regions. This could explain the differences in the neonatal mortality by geographical regions.

This study investigated neonatal mortality using a nationally representative sample of three survey conducted in 2003, 2008 and 2014. All the variables used in this study were self-reported and are therefore subject to the social desirability within the communities where the women lived in the Ghanaian context in general. Also, recall bias might have been introduced since the measures for births and socio-demographic variables were assessed retrospectively, within the past 5 years preceding the study. Differential misclassification of neonatal death, particularly early neonatal death as stillbirth among the respondents could lead to spurious associations. However, evidence from previous studies, which validated such measures in retrospective and longitudinal surveys suggests that these estimates are accurate and reliable [26]. Initial assessment of the health data in the DHS-I suggests that they are accurate estimates [27]. Furthermore, a recent study of the validity of the DHS neonatal mortality measures concluded that notwithstanding the limitations of the surveys, they provide the most reliable estimates of neonatal mortality in LMICs [28]. Moreover, the use of three population-based data in this study provides sufficient power for robust estimates.

The risk of dying within the first month of life was higher for early neonates. Moreover, rural residency, birth order and maternal obesity showed higher risk for neonatal death. Likewise, children of women living in regions other than the Greater Accra region had increased risk of neonatal death. Neonatal mortality is a global public health issue and accounts for inequalities in health not only between LMICs and high income countries but also within LMICs [29]. Therefore, this study adds to our understanding regarding the time to event and the socio-demographic dynamics and this important health outcome. The findings of this study implicate the important role of biological, environmental and geographical factors in neonatal mortality. The finding of higher risk of neonatal mortality among obese women has important implications for the emerging obesity in Ghana just as in other LMICs.

\section{Conclusion}

The risk of neonatal mortality is highest during the first week of life and it is socio-demographically patterned. Overall, 
the findings emphasise the need for a holistic approach to reducing neonatal mortality in order to realise the Sustainable Development Goal 3, which is aimed at reducing neonatal mortality to 12 per 1000 live births. Future studies investigating the influence of maternal morbidities, for example, gestational diabetes, preeclampsia, hypertension and other chronic diseases on neonatal mortality, especially in LMICs will increase our understanding further on the risk factors of neonatal mortality. This will shed light on effective neonatal survival interventions.

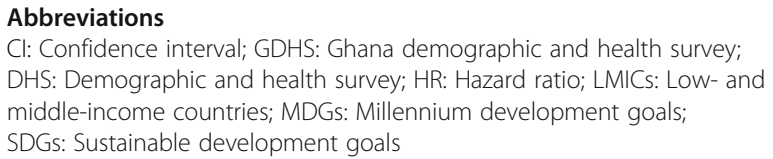

\section{Acknowledgements}

The author will like to thank Measure DHS for permission to analyse the data for publication.

\section{Author's contributions}

DTD conceptualised the study, conducted the data analysis, drafted the manuscript and revised it for publication. The author(s) read and approved the final manuscript.

\section{Authors' information}

Dr. David Teye Doku is an Associate Professor of Public Health and Epidemiology with the Department of Population and Health, University of Cape Coast, Ghana, and a Docent (Adjunct Professor) in Public Health at the Tampere University, Finland.

\section{Funding}

No funding was obtained for this study.

\section{Availability of data and materials}

The data is publicly available with permission from Measure DHS, USA.

\section{Declarations}

\section{Ethics approval and consent to participate}

Ethical approval for the GDHS was obtained from the Ghana Health Service Ethics Committee in Accra. All participants gave written consent.

\section{Consent for publication}

Participants gave consent to publish the results of the survey and permission to analyse the data was obtained from Measure DHS, USA.

\section{Competing interests}

None declared.

Received: 13 May 2021 Accepted: 17 December 2021

Published online: 07 January 2022

\section{References}

1. Lawn JE, Blencowe H, Oza S, You D, Lee AC, Waiswa P, et al. Every newborn: progress, priorities, and potential beyond survival. Lancet. 2014;384(9938): 189-205.

2. Lawn JE, Lee AC, Kinney M, Sibley L, Carlo WA, Paul VK, et al. Two million intrapartum-related stillbirths and neonatal deaths: where, why, and what can be done? Int J Gynecol Obstet. 2009;107:S5-19.

3. Liu L, Oza S, Hogan D, Chu Y, Perin J, Zhu J, et al. Global, regional, and national causes of under-5 mortality in 2000-15: an updated systematic analysis with implications for the sustainable development goals. Lancet. 2017;388(10063):3027-35
4. Ghana millennium development goal report. 2015. http://www.gh.undp. org/content/dam/ghana/docs/Doc/Inclgro/UNDP_GH_2015\%20Ghana\%2 OMDGs\%20Report.pdf. Accessed 07 Nov 2016.

5. United Nations. Sustainable development goals. 2015. http://www.un.org/susta inabledevelopment/sustainable-development-goals/. Accessed 02 Nov 2016.

6. Kayode GA, Ansah E, Agyepong IA, Amoakoh-Coleman M, Grobbee DE Klipstein-Grobusch K. Individual and community determinants of neonatal mortality in Ghana: a multilevel analysis. BMC Pregnancy Childbirth. 2014; 14(1):1.

7. DHS M. Standard recode manual for DHS 6. Calverton: MEASURE DHS USAID; 2013.

8. Kaplan EL, Meier P. Nonparametric estimation from incomplete observations. J Am Stat Assoc. 1958:53(282):457-81.

9. Clark TG, Bradburn MJ, Love SB, Altman DG. Survival analysis part I: basic concepts and first analyses. Br J Cancer. 2003;89(2):232-8.

10. Finlay JE, Özaltin E, Canning D. The association of maternal age with infant mortality, child anthropometric failure, diarrhoea and anaemia for first births: evidence from 55 low-and middle-income countries. BMJ Open. 2011;1(2):e000226.

11. Kozuki N, Lee AC, Silveira MF, Sania A, Vogel JP, Adair L, et al. The associations of parity and maternal age with small-for-gestational-age, preterm, and neonatal and infant mortality: a meta-analysis. BMC Public Health. 2013;13(3):1.

12. Simkhada $B$, Teijlingen ER, Porter M, Simkhada P. Factors affecting the utilization of antenatal care in developing countries: systematic review of the literature. J Adv Nurs. 2008;61(3):244-60.

13. Neupane S, Doku DT. Determinants of time of start of prenatal care and number of prenatal care visits during pregnancy among Nepalese women. J Community Health. 2012;37(4):865-73.

14. Doku D, Neupane S, Doku PN. Factors associated with reproductive health care utilization among Ghanaian women. BMC Int Health Hum Rights. 2012;12(1):1.

15. Gwatkin DR. Assessing economic inequalities in health: contribution of the INDEPTH health equity project. Measuring health equity in small areas: findings from demographic surveillance systems; 2005.

16. Houweling TA, Ronsmans C, Campbell OM, Kunst AE. Huge poor-rich inequalities in maternity care: an international comparative study of maternity and child care in developing countries. Bull World Health Organ. 2007:85(10):745-54.

17. Van de Poel E, Hosseinpoor AR, Speybroeck N, Van Ourti T, Vega J. Socioeconomic inequality in malnutrition in developing countries. Bull World Health Organ. 2008;86(4):282-91.

18. Houweling TA, Kunst AE. Socio-economic inequalities in childhood mortality in low-and middle-income countries: a review of the international evidence. Br Med Bull. 2010:93(1):7-26.

19. Saikia N, Shkolnikov VM, Jasilionis D. Trends and sub-national disparities in neonatal mortality in India from 1981 to 2011. Asian Popul Stud. 2016;12(1):88-107

20. Wang L. Determinants of child mortality in LDCs: empirical findings from demographic and health surveys. Health Policy. 2003;65(3):277-99.

21. Doku DT, Bhutta ZA, Neupane S. Associations of women's empowerment with neonatal, infant and under-5 mortality in low-and/middle-income countries: meta-analysis of individual participant data from 59 countries. BMJ Glob Health. 2020;5(1):e001558.

22. Ghana Statistical Service (GSS), Ghana Health Service (GHS), and ICF International. https://www.dhsprogram.com/pubs/pdf/FR221/FR221[13Aug2012].pdf.

23. Cresswell JA, Campbell OM, De Silva MJ, Filippi V. Effect of maternal obesity on neonatal death in sub-Saharan Africa: multivariable analysis of 27 national datasets. Lancet. 2012;380(9850):1325-30.

24. Neupane S, Prakash KC, Doku DT. Overweight and obesity among women: analysis of demographic and health survey data from 32 sub-Saharan African countries. BMC Public Health. 2016:16(1):1.

25. Doku DT, Neupane S. Double burden of malnutrition: increasing overweight and obesity and stall underweight trends among Ghanaian women. BMC Public Health. 2015;15(1):1

26. Garenne M, van Ginneken J. Comparison of retrospective surveys with a longitudinal follow-up in Senegal: SFS, DHS and Niakhar. Eur J Population. 1994:10(3):203-21.

27. Macro International Inc. An assessment of the quality of health data in DHS-I surveys. DHS methodological reports No.2. Calverton: Macro International Inc; 1993. 
28. McKinnon B, Harper S, Kaufman JS, Bergevin Y. Socioeconomic inequality in neonatal mortality in countries of low and middle income: a multicountry analysis. Lancet Glob Health. 2014;2(3):e165-73.

29. Neal S. The measurement of neonatal mortality: how reliable is

demographic and household survey data? CPC Working Paper 2012;25.

http://www.cpc.ac.uk/publications/cpc_working_papers/pdf/2012_WP25_

The_Measurement_of_Neonatal_Mortality_Neal.pdf. Accessed 28 Apr 2017.

\section{Publisher's Note}

Springer Nature remains neutral with regard to jurisdictional claims in published maps and institutional affiliations.

Ready to submit your research? Choose BMC and benefit from:

- fast, convenient online submission

- thorough peer review by experienced researchers in your field

- rapid publication on acceptance

- support for research data, including large and complex data types

- gold Open Access which fosters wider collaboration and increased citations

- maximum visibility for your research: over $100 \mathrm{M}$ website views per year

At $\mathrm{BMC}$, research is always in progress.

Learn more biomedcentral.com/submissions 